\title{
On the order of integration of monthly US ex-ante and ex-post real interest rates: new evidence from over a century of data
}

\author{
M. Karanasos, S.H. Sekioua, N. Zeng \\ University of Newcastle, Newcastle upon Tyne, UK
}

First draft: December 2004

\begin{abstract}
We use a long series of monthly data that spans over 100 years to examine the dynamics of US ex-post and ex-ante real interest rates. The principal tenet of this study is that the data are not consistent with a unit root in real interest rates, although shocks impinging upon these rates are rather persistent. In addition, our results highlight the importance of modeling long memory not only in the conditional mean but in the power transformed conditional variance as well. Overall, these findings suggest that much more attention needs to be paid to the degree of persistence and its consequences for the economic theories which are still inconsistent with the finding of either near-unit-root or long memory mean-reverting behavior.
\end{abstract}

Keywords: Dual long memory; Persistence; Real interest rate; Unit root tests.

JEL Classification: C22, E43.

We would like to thank C. Conrad and M. Karanassou for their helpful comments and suggestions. Addresses for correspondence:

M. Karanasos, Business School, University of Newcastle, Newcastle upon Tyne, NE1 7RU; email: menelaos.karanasos@ncl.ac.uk, tel: +44 (0)191 2227573, fax: +44 (0)191 2226584.

S.H. Sekioua, Business School, University of Newcastle, Newcastle upon Tyne, NE1 7RU; email: s.h.sekioua@ncl.ac.uk, tel: +44 (0)191 2227574, fax: +44 (0)191 2226584.

N. Zeng, Business School, University of Newcastle, Newcastle upon Tyne, NE1 7RU; email: ning.zeng@ncl.ac.uk. 


\section{Introduction}

In this paper, we investigate the integration properties of monthly US real interest rates. Our interest in the subject is motivated by the following four factors. First, the fact that an understanding of their dynamics is central to the study of prominent macroeconomic models and to the valuation of financial assets. Second, the number of economic theories which are inconsistent with the finding of nonstationarity. In particular, the long-run Fisher relationship requires the ex-ante real rate to be stationary. Third, developments of unit root tests with good size and power. Fourth, the empirical evidence to date concerning the order of integration of the US rates, which is rather mixed. For example, Sekioua (2004) suggests that they can be viewed as stationary albeit quite persistent processes, whereas Rapach and Weber (2004) conclude that they contain a unit root component. In sharp contrast, Rapach and Wohar (2004) find that the US quarterly postwar tax-adjusted real rates are consistent with either a high degree of persistence or a unit root. This evidence that the data may be generated by either an $\mathrm{I}(0)$ or $\mathrm{I}(1)$ process is at least indicative of fractional integration. Accordingly, Tsay (2000) argues that real rates do not contain a unit root but are fractionally integrated. ${ }^{1}$

Our empirical approach attempts to fill a gap in the literature in a number of ways. First, since the use of data on realized inflation can produce substantial small-sample bias in estimates of the Fisher relationship we employ both ex-ante and ex-post real interest rates. Second, we employ two unit root tests recently developed by Elliott et al. (1996) and Ng and Perron (2001). We also use the test proposed by Hansen (1999), which allows for the construction of confidence intervals for the largest roots of autoregressive processes. Third, to overcome the small-sample bias and, most importantly, to increase the power of the tests we use a long series of monthly data that spans over 100 years. Fourth, we estimate the two main parameters driving the degree of persistence in the real interest rate and its uncertainty using a fractionally integrated ARMA-asymmetric power ARCH (ARFIMA-FIAPARCH) process. This model is sufficiently flexible to handle the dual long memory behavior encountered in the real US rates.

This study provides evidence that the US real interest rates exhibit dual long memory with orders of integration which differ significantly from zero and unity. Persistence, in the present context, is problematic not just for the Fisher hypothesis but also for the consumption based capital asset pricing model (CCAPM). The CCAPM implies that the growth rate of consumption and the real interest rate should have similar time-series characteristics. Still, the growth rate of consumption has been found to contain no unit root and does not exhibit the persistence apparent in real interest rates (Rapach and Wohar, 2004). Thus, although in finding no unit root, the results might have been seen as resolving the puzzling irregularity concerning the behavior of interest rates implied by the CCAPM, the observed persistence means that another irregularity emerges.

\section{Empirical methodology}

\subsection{Unit root tests}

We test for a unit root in the real interest rate using recently proposed tests, the efficient generalized least squares (GLS) version of the Dickey-Fuller (DF) test due to Elliott et al. (1996) and the Ng and Perron (2001) test. While most unit root tests are only concerned with testing the null hypothesis that the largest root of an autoregressive $\mathrm{AR}(k)$ process is unity $\left(\mathrm{H}_{0}: \alpha=1\right)$ against the alternative that it is less than one, the DF-GLS method tests the null against a specific alternative $\mathrm{H}_{1}: \alpha<1$ where $\alpha$ is set as local-to-unity $(1+c / T)$ and holding $c$ fixed as $T \rightarrow \infty$. Further, using a sequence of tests of the null of a unit root against a set of stationary persistent alternatives, Elliott et al. (1996) showed substantial power gain from the DF-GLS method over the conventional augmented DF test (which has low power against close alternatives so that the unit root null can seldom be rejected for highly persistent variables). The unit root test of $\mathrm{Ng}$ and Perron (2001), which follow Elliott et al. (1996) by using local-to-unity GLS detrending, has also been shown to have good size and power properties. Nonetheless, whilst these two tests are more powerful than the traditional ADF test, rejection of the unit root hypothesis leaves us with little information on the actual persistence and speed of mean reversion of the real interest rate.

\footnotetext{
${ }^{1}$ However, this article has not explored the time-dependent heteroscedasticity in the second conditional moment of the real intereste rate process.
} 
To remedy this, we use the grid bootstrap method of Hansen (1999), which allows for the construction of confidence intervals for $\alpha$, the largest root of the following ADF equation:

$$
r_{t}=\alpha r_{t-1}+\sum_{i=1}^{k-1} \Delta r_{t-i}+\varepsilon_{t},
$$

Hansen's grid bootstrap has been shown, using Monte Carlo simulations, to yield accurate confidence intervals and unbiased estimates in large samples. The lag lengths used in the aforementioned tests are chosen with the modified AIC (MAIC) of Ng and Perron (2001) as it produces the best combination of size and power. It must be stressed, however, that the long lags selected by MAIC, see table 1, are not surprising. MAIC is designed to select relatively long lag lengths in the presence of roots $(\alpha)$ near unity and shorter lags in the absence of such roots.

Finally, we use the KPSS test statistic $\left(\eta_{\mu}\right)$ of Kwiatkowski et al. (1992) to test the null hypothesis of level stationarity $\mathrm{I}(0)$ against a unit root alternative. Essentially, if the tests reject the unit root and stationarity hypotheses, then the US rates may potentially be fractionally integrated processes.

\subsection{ARFIMA-FIAPARCH model}

The traditional ARMA and ARIMA specifications are incapable of imparting the persistence to real rates that we find in the data. Put differently, by viewing the real interest rate as an $\mathrm{I}(0)$ or $\mathrm{I}(1)$ process instead of an $\mathrm{I}(d)$ process, we bias downward or upward our estimate of its persistence.

In this section, we present the ARFIMA-FIAPARCH model ${ }^{2}$, which generates the long memory property in both the first and (power transformed)second conditional moments and is thus sufficiently flexible to handle the dual long memory behavior encountered in the real interest rate. In the $\operatorname{ARFIMA}\left(p, d_{m}, 0\right)$ FIAPARCH $\left(1, d_{v}, 1\right)$ model the mean equation is defined as:

$$
\left(1-\phi_{1} L-\ldots-\phi_{p} L^{p}\right)(1-L)^{d_{m}}\left(r_{t}-\mu\right)=\varepsilon_{t},
$$

where $r_{t}$ denotes the real rate and $0 \leq d_{m} \leq 1 ; \varepsilon_{t}$ is conditionally normal with mean zero and variance $h_{t}$. That is $\varepsilon_{t} \mid \Omega_{t-1} \sim N\left(0, h_{t}\right)$, where $\Omega_{t-1}$ is the information set up to time $t-1$. The structure of the conditional variance is:

$$
h_{t}^{\frac{\delta}{2}}=\omega+\left[1-\frac{(1-\varphi L)(1-L)^{d_{v}}}{1-\beta L}\right]\left[\left|\varepsilon_{t}\right|-\gamma \varepsilon_{t}\right]^{\delta},
$$

where $0 \leq d_{v} \leq 1, \omega, \delta>0, \varphi, \beta<1$ and $-1<\gamma<1$ (see Tse, 1998).

The two common values of the power term $(\delta)$ imposed throughout much of the GARCH literature are the values of two and unity. The invalid imposition of a particular value for the power term may lead to suboptimal modeling and forecasting performance.

The ARFIMA-FIAPARCH model has the advantage of keeping the elegance of the ARMA-GARCH model while enhancing its dynamics. Put differently, it has at least two important implications for our understanding of the real rate and its uncertainty. First, it recognizes the long memory aspect of the interest rate and provides an empirical measure of real uncertainty that accounts for long memory in the power transformed conditional variance of the interest rate process. Second, it allows for a more systematic comparison of many possible models that can capture the features of the real interest rate series.

\section{Empirical results}

The data is extracted from the www.globalfindata.com database and includes the monthly long-term government bond yield and the consumer price index (CPI) series for the US spanning the period from 1876 to 2000 . Of course, there is the potential problem of structural instability when using a long span of data. However, the dynamics of the US real interest rates appear to be relatively stable over our sample period. Also, the expected values of inflation used to construct the ex-ante rate are obtained by means of a preliminary signal extraction procedure. Signal extraction is a procedure used to separate unobservable

\footnotetext{
${ }^{2}$ The properties of this model are investigated in Conrad and Karanasos (2005).
} 
components, expected values in our case, from an observable variable containing noise. This is achieved through the application of the law of iterated projections by means of the Kalman filter technique. The estimated model is the following:

$$
r_{t}=\xi_{t}+v_{t}, \quad \xi_{t+1}=\xi_{t}+\zeta_{t},
$$

where $\xi_{t}$ is a vector of possibly unobserved state variables and $v_{t}$ and $\zeta_{t}$ are vectors of mean zero, Gaussian disturbances. The two expressions are the signal and state equations, respectively.

We begin our analysis by implementing the unit root tests. From Table 1, one can see that the DFGLS and Ng and Perron (2001) tests reject the unit root null unequivocally at the $1 \%$ level of significance. This is an important result since it contrasts sharply with what has been reported in earlier studies on real interest rates which were essentially based on shorter samples and weaker statistical tests than those we are using. Nevertheless, the point estimates and upper limits of the grid bootstrap intervals reveal that although the root of equation (1) is not unity, it is still very close to the unit root boundary. Interestingly, it appears that the results are not critically dependent on how rates are measured, whether ex-post or ex-ante, since $\alpha$ for both is close to unity. Hence, if forecast errors are to blame for the failure to detect mean-reversion in small samples due to peso problems, then the fact that there is no substantial difference between ex-post and ex-ante rates in terms of $\alpha$ means that these errors are likely to be much smaller over long periods than over shorter periods.

In addition, the KPSS test rejects the stationarity null hypothesis for both rates. Therefore, with the two US real interest rates we find evidence against the unit root as well as the stationarity hypotheses. Although these tests are merely suggestive, the overall evidence indicates the need to go beyond the $\mathrm{I}(1) / \mathrm{I}(0)$ framework. Thus, fractional integration allowing for long memory is a plausible alternative (see also Lai., 1997).

Table 1: Unit root tests.

\begin{tabular}{|c|c|c|c|c|c|c|c|c|c|}
\hline & $\eta_{\mu}$ & $\overline{\mathrm{MZ}_{\alpha}}$ & $\overline{\mathrm{MZ}_{t}}$ & $\overline{\text { DF-GLS }}$ & $\alpha$ & $\begin{array}{c}95 \\
\text { (lower) }\end{array}$ & $\begin{array}{c}95 \\
\text { (upper) }\end{array}$ & $\begin{array}{c}99 \\
\text { (lower) }\end{array}$ & $\begin{array}{c}99 \\
99 \\
\text { (upper) }\end{array}$ \\
\hline ex-post & 0.770 & -20.404 & -3.177 & -3.064 & 0.977 & 0.968 & 0.988 & 0.965 & 0.991 \\
\hline ex-ante & 0.771 & -19.821 & -3.132 & -3.040 & 0.983 & 0.975 & 0.993 & 0.973 & 0.995 \\
\hline $\begin{array}{l}\text { Notes: } \\
\text { The ol } \\
\text { respec } \\
\text { interva } \\
\text { The } 19 \\
\left(\mathrm{MZ}_{\alpha}\right.\end{array}$ & $\begin{array}{l}\text { The ban } \\
\text { imal lag } \\
\text { vely) are } \\
\text { were cc } \\
\text { critical } \\
\text { nd } \mathrm{MZ}_{t}\end{array}$ & $\begin{array}{l}\text { vith for th } \\
\text { engths for } \\
\text { et accord } \\
\text { structed } \\
\text { alues are: } \\
\text { espective }\end{array}$ & $\begin{array}{l}\text { KPSS ( } \\
\text { he unit } \\
\text { g to the } \\
\text { ing } 1999 \\
.739 \text { for } \\
) ;-2.56 \mathrm{f}\end{array}$ & $\begin{array}{l}\text { ) test is ch } \\
\text { ot tests ( } 13 \\
\text { nodified AI } \\
\text { ootstrap re } \\
;-13.8 \text { and } \\
\text { the DF-GI }\end{array}$ & $\begin{array}{l}\text { sen with } \\
\text { nd } 14 \text { fo } \\
\text { The } 95 \\
\text { ications } \\
2.58 \text { for } \\
\text { statisti }\end{array}$ & $\begin{array}{l}\text { Newey- } \\
\text { the ex- } \\
\text { and } 9 \\
\text { t each } \\
\text { he } \mathrm{Ng} \text { a }\end{array}$ & $\begin{array}{l}\text { st usin } \\
\text { st and } \\
\text { bootst } \\
200 \text { gri } \\
\text { Perror }\end{array}$ & $\begin{array}{l}\text { artlett } \mathrm{k} \\
\text { ante rate } \\
\text { confide } \\
\text { ints. } \\
\text { atistics }\end{array}$ & \\
\hline
\end{tabular}

Next, we proceed with the estimation of the $\operatorname{ARFIMA}\left(p, d_{m}, 0\right)-\operatorname{FIAPARCH}\left(1, d_{v}, 1\right)$ model in equations (2) and (3) in order to take into account the serial correlation observed in the levels (and their power transformations) of our time series data, and to capture the possible long memory in the conditional mean and the power transformed conditional variance. We estimate the ARFIMA-FIAPARCH models using the quasi maximum likelihood estimation (QMLE) method as implemented by Laurent and Peters (2002) in Ox. In view of the characteristic incidence of outliers in the data, the Student's $t$ distribution is assumed for the disturbances. Table 2 reports the results for the period 1876-2003.

Table 2: ARFIMA-FIAPARCH models.

\begin{tabular}{ccccccccccc}
\hline \hline & $\widehat{d}_{m}$ & $\widehat{\phi}_{1}$ & $\widehat{\phi}_{2}^{a}$ & $\widehat{\omega}$ & $\widehat{d}_{v}$ & $\widehat{\delta}$ & $\widehat{\varphi}$ & $\widehat{\beta}$ & $\widehat{\gamma}$ & $\widehat{t}$ \\
\hline ex-post & 0.26 & 0.79 & 0.13 & 5.68 & 0.83 & 1.74 & 0.10 & 0.88 & 0.26 & 6.34 \\
& $(6.13)$ & $(16.65)$ & $(3.52)$ & $(2.04)$ & $(12.23)$ & $(10.41)$ & $(1.85)$ & $(32.04)$ & $(2.30)$ & $(4.44)$ \\
ex-ante & 0.40 & 0.93 & -0.21 & 0.01 & 0.90 & $2^{b}$ & 0.11 & 0.89 & 0.16 & 7.14 \\
& $(5.38)$ & $(12.36)$ & $(4.86)$ & $(1.35)$ & $(12.30)$ & - & $(1.68)$ & $(36.65)$ & $(2.18)$ & $(4.31)$ \\
\hline
\end{tabular}

Notes: For each of the two series, table 2 reports QMLE parameter estimates

for the ARFIMA-FIAPARCH model. The numbers in parentheses are absolute t-statistics.

${ }^{a}$ For the ex-ante rate we estimate a $\hat{\phi}_{3}$ of $0.17(5.25) ;{ }^{b}$ the estimated value of $\delta$ is 1.96

and not significantly different from 2. $t$ are the degrees of freedom for the Student's $t$

distribution. The estimates of $\mu$ have been omitted to save space. 
The best fitted model is chosen according to the minimum values of the Schwarz information criterion (SIC). We choose a $\operatorname{FIAPARCH}\left(1, d_{v}, 1\right)$ specification for the power transformed conditional variances and ARFIMA models of orders $\left(2, d_{m}, 0\right)$ and $\left(3, d_{m}, 0\right)$ for the ex-post and ex-ante rates respectively. The autoregressive parameters $\left(\phi_{1}, \phi_{2}, \phi_{3}\right)$ were necessary to account for the significant autocorrelation, which is evident in both series. The estimated ARCH parameters $(\widehat{\varphi}, \widehat{\beta})$ for the US rates are significant and satisfy the set of conditions sufficient to guarantee the nonnegativity of the conditional variance (see Conrad and Haag, 2005). For both series negative shocks predict higher volatility than positive shocks, since the estimated asymmetry coefficient $(\widehat{\gamma})$ is significant and positive. The estimated values of $d_{m}$ for the ex-post and ex-ante rates are 0.26 and 0.40 , respectively, which are significantly different from zero at the $1 \%$ level and imply some strong long-memory features. In both cases the estimates for the fractional differencing parameter $\left(\widehat{d}_{v}\right)$ are relatively large and statistically significant. For the ex-ante rate the power term is not significantly different from two.

To test for the persistence in the two conditional moments of the two series, we examine the likelihood ratio (LR) tests for the linear constraints $d_{m}=0$ ('ARMA' model), $d_{v}=0$ ('APARCH' model) and $d_{m}=d_{v}=0$ ('ARMA-APARCH' model). As seen in Table 3 for both rates the LR statistics clearly reject the 'ARMA' and the 'APARCH' null hypotheses against the ARFIMA-FIAPARCH model. The evidence obtained from the LR tests is reinforced by the model ranking provided by the SIC model selection criterion. In both cases the criterion (not reported) favors the ARFIMA-FIAPARCH model over both the ARMA-FIAPARCH and ARFIMA-APARCH models. Hence, from the various diagnostic statistics it appears that monthly US real interest rate has long memory behavior in both its first and its (power transformed)second conditional moments.

Table 3: Tests of fractional differencing parameters in the first and second conditional moments.

\begin{tabular}{|c|c|c|c|c|c|}
\hline & \multicolumn{3}{|c|}{$\begin{array}{c}\mathrm{H}_{0}: \mathrm{ARMA} \\
\left(d_{m}=0\right)\end{array}$} & $\begin{array}{c}\mathrm{H}_{0}: \underset{\left(d_{v}=0\right)}{\mathrm{APARCH}} \\
\mathrm{LR}\end{array}$ & $\begin{array}{c}\mathrm{H}_{0}: \text { ARMA-APARCH } \\
\left(d_{m}=0, d_{v}=0\right) \\
\mathrm{LR}\end{array}$ \\
\hline ex-post & $\begin{array}{c}0.26 \\
\{0.04\}\end{array}$ & $\begin{array}{c}27.48 \\
{[0.00]}\end{array}$ & $\begin{array}{c}0.83 \\
\{0.07\}\end{array}$ & $\begin{array}{l}8.42 \\
{[0.00]}\end{array}$ & $\begin{array}{c}34.40 \\
{[0.00]}\end{array}$ \\
\hline ex-ante & $\begin{array}{c}0.40 \\
\{0.07\}\end{array}$ & $\begin{array}{c}27.95 \\
{[0.00]}\end{array}$ & $\begin{array}{c}0.90 \\
\{0.07\}\end{array}$ & $\begin{array}{l}1.85 \\
{[0.17]}\end{array}$ & $\begin{array}{c}28.52 \\
{[0.00]}\end{array}$ \\
\hline \multicolumn{6}{|c|}{$\begin{array}{l}\text { Notes: Columns } 2,4 \text { and } 5 \text { report the value of the following likelihood ratio test: } \\
\mathrm{LR}=2\left[\mathrm{ML}_{u}-\mathrm{ML}_{r}\right] \text {, where } \mathrm{ML}_{u} \text { and } \mathrm{ML}_{r} \text { denote the maximum log-likelihood values } \\
\text { of the unrestricted and restricted models respectively. The numbers in }[\cdot] \text { are } \\
\text { p-values. The numbers in }\{\cdot\} \text { are standard errors. }\end{array}$} \\
\hline
\end{tabular}

\section{Conclusions}

In this paper, we have examined the long-term persistence of ex-ante and ex-post US real interest rates. Our responses to the problem of low power of the standard unit root tests were twofold. First, we employed recently developed econometric techniques that greatly improve the power of these tests. Second, we used a long span of monthly data covering more than a century. Our results show that the US real rate displays near integrated behavior, precisely the type of stationary behavior that will be difficult for standard tests to detect for samples as short as the post war era which are typically used in the extant literature.

However, recognizing that the knife-edge distinction between $\mathrm{I}(0)$ and $\mathrm{I}(1)$ processes can be far too restrictive, we also investigated the long memory aspect of the US interest rates and provided an empirical measure of its uncertainty that accounts for long memory in the second conditional moment of the real interest rate process. Analogous to the issues pertaining to the proper modeling of the long-run dynamics in the conditional mean of the real US rate, similar questions, therefore, become relevant in the modeling of its conditional volatility.

Finally, Rapach and Wohar (2004) find that real US consumption growth exhibits very mild persistence. These significant differences in the degree of persistence for the US real interest rate and consumption growth imply sustained violations of the Euler condition at the center of the consumption-based asset pricing model. Hence, we reemphasize Rapach and Wohar's point: a quite persistent real interest 
rate, due to either near-unit-root or long memory mean reverting behavior, has important theoretical implications for the CCAPM model.

\section{References}

Conrad, C. and Haag, B. (2004). Inequality constraints in the FIGARCH model. Unpublished Manuscript, University of Manheim.

Conrad, C. and Karanasos, M. (2005). The dual long memory process revisited: inequality constraints, impulse response weights, and autocorrelation coefficients. Unpublished manuscript, University of Newcastle.

Elliott, G., Rothenberg, T. and Stock, J.H. (1996). Efficient tests for an autoregressive unit root. Econometrica, 64, pp. 813-836.

Hansen, B. (1999). The grid bootstrap and the autoregressive model. The Review of Economics and Statistics, 81, pp. 594-607.

Kwiatkowski, D., Phillips, P.C.B., Schmidt, P. and Shin, Y. (1992). Testing the null hypothesis of stationarity against the alternative of a unit root: how sure are we that economic series are non stationary? Journal of Econometrics 54, pp. 159-178.

Lai, K.S. (1997). Long-term persistence in the real interest rate: some evidence of a fractional unit root? International Journal of Finance and Economics, 2, pp. 225-235.

Laurent, S. and Peters, J.P. (2002). G@ARCH 2.2: an Ox package for estimating and forecasting various ARCH models. Journal of Economic Surveys, 3, pp. 447-485.

$\mathrm{Ng}$, S. and Perron, P. (2001). Lag length selection and the construction of unit root tests with good size and power. Econometrica, 69, pp. 1519-1554.

Rapach, D.E. and Weber, C.E. (2004). Are real interest rates really nonstationary? new evidence from tests with good size and power. Journal of Macroeconomics, 26, pp. 409-430.

Rapach, D.E. and Wohar, M.E. (2004). The persistence in international real interest rates. International Journal of Finance and Economics, forthcoming.

Sekioua, S.H. (2004). The real interest rate: is it mean-reverting? If yes, how long does it take to mean-revert? Unpublished manuscript, University of Newcastle.

Tsay, W.J. (2000). Long memory story of the real interest rate. Economics Letters, 67, pp. 325-330.

Tse, Y.K. (1998). The conditional heteroscedasticity of the yen-dollar exchange rate. Journal of Applied Econometrics, 13, pp. 49-55. 